\title{
DETERMINAN PENCEGAHAN OSTEOPOROSIS PADA WANITA MENOPAUSE
}

\author{
Riska Wildawati ${ }^{1}$, Yecy Anggreny ${ }^{2}$, Dewi Kurnia Putri ${ }^{3}$ \\ ${ }^{1,2,3}$ Program Studi Keperawatan STIKes Hangtuah Pekanbaru \\ STIKes Hang Tuah Pekanbaru Jalan Mustafa Sari No. 5 \\ Tangkerang Selatan Pekanbaru Riau Kode Pos 28000 Indonesia \\ Email : riskawildawati066@gmail.com
}

\begin{abstract}
Abstrak
Wanita menopause berisiko terkena osteoporosis. Osteoporosis merupakan penyakit yang ditandai dengan rendahnya masa tulang yang menyebabkan tulang mudah rapuh dan berisiko fraktur, untuk menghindari risiko osteoporosis maka diperlukan upaya pencegahan. Tujuan penelitian untuk mengetahui determinan pencegahan osteoporosis pada wanita menopause. Jenis penelitian kuantitatif analitik dengan metode korelasi dan pendekatan cross sectional. Populasi adalah wanita menopause berusia 50-60 tahun dengan jumlah sampel 182 orang dan menggunakan teknik purposive sampling. Data dianalisis secara univariat dan bivariat. Analisi univariat menggunakan distribusi frekuensi dan bivariat menggunakan uji chi square. Hasil penelitian menunjukkan $42,3 \%$ diantaranya tidak melakukan pencegahan osteoporosis. Terdapat hubungan antara sikap ( $p$ value 0,000 , nilai $\mathrm{POR}=9,2$ ), dukungan keluarga ( $p$ value 0,000 , nilai $\mathrm{POR}=9,95$ ) dan gaya hidup ( $p$ value 0,000 , nilai $\mathrm{POR}=8$ ) terhadap pencegahan osteoporosis pada wanita menopause. Disimpulkan bahwa osteoporosis dapat dipengaruhi oleh sikap, dukungan keluarga dan gaya hidup. Diharapkan wanita menopause agar dapat menerapkan pencegahan osteoporosis terutama dalam menyikapi pengetahuan yang didapatkan tentang osteoporosis, merubah gaya hidup lebih sehat dan pihak keluarga dapat membantu pemenuhan kebutuhan kalsium pada wanita menopause.
\end{abstract}

Kata kunci: Dukungan Keluarga, Gaya Hidup, Sikap, Osteoporosis

\begin{abstract}
Menopause woman are at osteoporosis risk. Osteoporosis is a disease signed by low bone mass which causing bones are easily fragile and at fracture risk, to avoid the osteoporosis risk, so that needed the preventive effort. This research purpose is to knowing the determinants of osteoporosis prevention on menopause women. This research type is analytic quantitative with correlaation method and cross sectional design approach. Population are women menopause that aged 50-60 years old with amount of sample are 182 peoples, by purposive sampling technique. The data was analyzed as univariate and bivariate, by univariate are using frequency distribution and by bivariate are using chi square test. The research results showed that, $42.3 \%$ had never done osteoporosis prevention.Then there are corellation among attitude ( $p$ value 0.000, POR value $=9.2$ ), family support ( $p$ value 0.000, POR value $=9.95$ and life style ( $p$ value 0.000 , POR value $=8$ ) on osteoporosis prevention on menopause women. In this research, osteoporosis can be influenced by attitudes, family support and lifestyle.It is expected to menopause women so that implementing the osteoporosis prevention, specially in responding to knowledge which obtained about osteoporosis change the lifestyle to bo more health, and family can helping to fulfillment of calcium needs on menopause women.
\end{abstract}

Keywords : Attitude, Family Support, Lifestyle, Osteoporosis

\section{PENDAHULUAN}

Menopause merupakan suatu proses akhir dari siklus menstruasi karena menurunnya produksi hormon estrogen yang dihasilkan oleh ovarium. Masa menopause biasanya terjadi pada usia 45-55 tahun. Saat ini, di Amerika Serikat wanita yang telah mengalami menopause lebih dari 32 juta dan 
Rizka Wildawati ${ }^{1}$, Yecy Anggreny ${ }^{2}$, Dewi Kurnia Putri ${ }^{3}$, Determinan Pencegahan Osteoprosis pada Wanita Menopause

usia yang mengalami menopause rata-rata pada usia 50-52 tahun (Mulyani, 2013).

Di Indonesia Wanita yang telah menopause berjumlah 25,32 juta jiwa pada tahunn 2008, diprediksi terjadi peningkatan sekitar 14 atau sekitar 30,3 juta jiwa pada tahun 2020. Sedangkan pada tahun 2015, di Provinsi Riau ada sebanyak 344,846 orang wanita yang mengalami menopause pada usia 50-74 tahun (Dinas Kesehatan Provinsi Riau, 2015).

Osteoporosis merupakan suatu penyakit yang ditandai dengan rendahnya suatu masa tulang atau tulang menjadi rapuh dan dapat menimbulkan risiko terjadinya fraktur (Helmi, 2012). Wanita yang telah mengalami menopause berisiko tinggi 5,6 kali mengalami osteoporosis. Wanita yang mengalami menopause akan mengalami penyusutan massa tulang sekitar 40-50\%, hal ini dipengaruhi oleh produktivitas hormon estrogen (Mulyani, 2013). Osteoporosis yang dialami oleh wanita menopause juga disebabkan oleh beberapa faktor seperti riwayat penyakit tertentu, kebiasaan mengkonsumsi obat-obatan berkelanjutan, wanita yang melahirkan lebih dari 3 kali dan kekurangan status gizi (Prihatini, Mahirawati, Jahari \& Sudiman, 2010).

Upaya pencegahan osteoporosis bisa dengan melakukan olahraga karena dapat melatih tulang menjadi lebih kuat, padat dan keras, dan cara ini dapat dilakukan sejak dini agar dapat melindungi tulang dan kinerja tulang dapat mengalami peningkatan. Tetapi upaya ini tidak boleh dilakukan secara berlebihan terutama bagi wanita, karena jika melakukan olahraga secara berlebihan dapat memicu terjadinya osteoporosis akibat pengaruh dari hormon estrogen yang menurun, selain itu ada obat-obatan seperti anti peradangan, obat anti kejang, obat maag antasida dan heparin yang dapat meningkatkan risiko osteoporosis (Tjahjadi, 2009). Penelitian ini bertujuan untuk mengetahui determinan pencegahan osteoporosis pada wanita menopause.

\section{METODE PENELITIAN}

Jenis penelitian adalah kuantitatif analitik dan desain yang digunakan adalah cross sectional. Responden penelitian berjumlah 182 orang. Penelitian di lakukan di wilayah kerja puskesmas Payung Sekaki kota Pekanbaru. Teknik sampling yang digunakan adalah purposive sampling. Sebelumnya responden harus menandatangani lembar persetujuan menjadi responden. Analisis yang digunakan adalah analisis univariat, analisa bivariat.

\section{HASIL PENELITIAN}

\section{Analisis Univariat}

Tabel 1.

Karakteristik usia wanita menopause di wilayah kerja puskesmas Payung Sekaki

\begin{tabular}{llllll}
\hline Karakteristik & Mean & Median & Min & Max & SD \\
\hline Usia & 54,60 & 54,00 & 50 & 60 & 2,991
\end{tabular}


Berdasarkan tabel 1 diatas dapat dilihat dari 182 responden rerata usia wanita menopause adalah 54,60 tahun, dengan usia minimum 50 tahun dan maksimum 60 tahun dengan standar deviasi 2,991.

\section{Tabel 2.}

Distribusi frekuensi responden berdasarkan karakteristik wanita menopause di wilayah kerja puskesmas Payung Sekaki

\begin{tabular}{lcc}
\hline \multicolumn{1}{c}{ Karakteristik } & Frekuensi & Persentase (\%) \\
\hline Ibu tinggal & & \\
bersama & & \\
- Keluarga & 101 & 55,5 \\
- Suami & 43 & 23,6 \\
- Anak & 38 & 20,9 \\
\hline \multicolumn{1}{c}{ Total } & 182 & 100 \\
\hline
\end{tabular}

Berdasarkan tabel 2 karakteristik ibu tinggal bersama keluarga sebanyak 101 dengan persentase $55,5 \%$.

Tabel 3.

Distribusi frekuensi determinan pencegahan osteoporosis pada wanita menopause

\begin{tabular}{|c|c|c|c|}
\hline No & Variabel & Frekuensi & Persentase \\
\hline \multicolumn{4}{|c|}{ Variabel dependen } \\
\hline \multirow[t]{3}{*}{1} & Pencegahan osteopo & osis & \\
\hline & - Tidak melakukan & 77 & 42,3 \\
\hline & - Melakukan & 105 & 57,7 \\
\hline \multicolumn{4}{|c|}{ Variabel independen } \\
\hline \multirow[t]{3}{*}{2} & Pengetahuan & & \\
\hline & - Cukup & 27 & 14,8 \\
\hline & - Baik & 155 & 85,2 \\
\hline \multirow[t]{3}{*}{3} & Sikap & & \\
\hline & - Negatif & 84 & 46,2 \\
\hline & - Positif & 98 & 53,8 \\
\hline \multirow[t]{3}{*}{4} & Dukungan Keluarga & & \\
\hline & $\begin{array}{l}\text { - Tidak } \\
\text { mendukung }\end{array}$ & 85 & 46,7 \\
\hline & - Mendukung & 97 & 53,3 \\
\hline \multirow[t]{3}{*}{5} & Gaya Hidup & & \\
\hline & - Negatif & 87 & 47,8 \\
\hline & - Positif & 95 & 52,2 \\
\hline
\end{tabular}

Berdasarkan tabel 3, dari 182 responden wanita menopause yang melakukan pencegahan osteoporosis sebanyak 105 $(57,7 \%)$, pengetahuan kategori cukup sebanyak 27 orang $(14,8 \%)$, sikap negatif terhadap pencegahan osteoporosis sebanyak 84 orang (46,2\%). Dukungan keluarga yang tidak mendukung pencegahan osteoporosis sebanyak 85 orang $(46,7 \%)$ dan gaya hidup yang negatif sebanyak 87 orang $(47,8 \%)$.

\section{Analisis Bivariat}

Tabel 4.

Hubungan pengetahuan terhadap pencegahan osteoporosis pada wanita menopause

\begin{tabular}{|c|c|c|c|c|c|c|}
\hline \multirow{3}{*}{$\begin{array}{c}\text { Pengeta } \\
\text { huan }\end{array}$} & \multicolumn{4}{|c|}{ Pencegahan } & \multirow{2}{*}{\multicolumn{2}{|c|}{ Total }} \\
\hline & \multicolumn{2}{|c|}{$\begin{array}{c}\text { Tidak } \\
\text { melakukan }\end{array}$} & \multicolumn{2}{|c|}{ Melakukan } & & \\
\hline & $\mathrm{n}$ & $(\%)$ & $n$ & $(\%)$ & $n$ & $(\%)$ \\
\hline Cukup & 13 & 48,1 & 14 & 51,9 & 27 & 100 \\
\hline Baik & 64 & 41,3 & 91 & 58,7 & 155 & 100 \\
\hline Total & 77 & 42,3 & 105 & 57,7 & 182 & 100 \\
\hline
\end{tabular}

Berdasarkan tabel 4, dari 27 responden dengan pengetahuan cukup, 13 responden $(48,1 \%)$ diantaranya tidak melakukan pencegahan osteoporosis dan dari 155 responden yang pengetahuannya baik, 64 responden $(41,3 \%)$ diantaranya tidak melakukan pencegahan osteoporosis. Hasil uji Chi Square diperoleh $p$ value 0,506>a $(0,05)$, maka secara statistik tidak terdapat hubungan yang signifikan antara pengetahuan terhadap pencegahan osteoporosis pada wanita menopause. 
Rizka Wildawati ${ }^{1}$, Yecy Anggreny ${ }^{2}$, Dewi Kurnia Putri ${ }^{3}$, Determinan Pencegahan Osteoprosis pada Wanita Menopause

Tabel 5.

Hubungan sikap terhadap pencegahan osteoporosis pada wanita menopause

\begin{tabular}{lcccccc}
\hline \multirow{3}{*}{ Sikap } & \multicolumn{4}{c}{ Pencegahan } & \multicolumn{2}{c}{ Total } \\
\cline { 2 - 6 } & \multicolumn{2}{c}{$\begin{array}{c}\text { Tidak } \\
\text { melakukan }\end{array}$} & \multicolumn{2}{c}{$\begin{array}{c}\text { Melaku } \\
\text { Kan }\end{array}$} & \multicolumn{2}{l}{ Totann } \\
\cline { 2 - 6 } & $\mathrm{n}$ & $(\%)$ & $\mathrm{n}$ & $(\%)$ & $\mathrm{n}$ & $(\%)$ \\
\hline Negatif & 58 & 69 & 26 & 31 & 84 & 100 \\
Positif & 19 & 19,4 & 79 & 80,6 & 98 & 100 \\
\hline Total & 77 & 42,3 & 105 & 57,7 & 182 & 100 \\
\hline
\end{tabular}

Berdasarkan tabel 5 didapatkan hasil dari 84 responden dengan sikap negatif, 58 diantaranya $(69 \%)$ tidak melakukan pencegahan osteoporosis dan dari 98 responden dengan sikap positif, 19 responden $(19,4 \%)$ diantaranya tidak melakukan pencegahan osteoporosis. Hasil uji Chi Square yang diperoleh $p$ value $0,000<\alpha$ $(0,05)$ hal ini berarti secara statistik dapat disimpulkan terdapat hubungan yang signifikan antara sikap terhadap pencegahan osteoporosis pada wanita menopause.

Tabel 6.

Hubungan dukungan keluarga terhadap pencegahan osteoporosis pada wanita menopause

\begin{tabular}{|c|c|c|c|c|c|c|}
\hline \multirow{3}{*}{$\begin{array}{c}\text { Dukungan } \\
\text { keluarga }\end{array}$} & \multicolumn{4}{|c|}{ Pencegahan } & \multirow{2}{*}{\multicolumn{2}{|c|}{ Total }} \\
\hline & \multicolumn{2}{|c|}{$\begin{array}{c}\text { Tidak } \\
\text { Melakuk } \\
\text { an } \\
\end{array}$} & \multicolumn{2}{|c|}{$\begin{array}{c}\text { Melaku } \\
\text { kan }\end{array}$} & & \\
\hline & $\mathrm{n}$ & $(\%)$ & $\mathrm{n}$ & $(\%)$ & $\mathrm{n}$ & $(\%)$ \\
\hline Tidak & 59 & 69,4 & 26 & 30,6 & 85 & 100 \\
\hline Mendukung & & & & & & \\
\hline Mendukung & 18 & 18,6 & 79 & 81,4 & 97 & 100 \\
\hline Total & 77 & 42,3 & 105 & 57,7 & 182 & 100 \\
\hline
\end{tabular}

Berdasarkan tabel 6 didapatkan hasil dari 85 responden yang dukungan

Tabel 7.

Hubungan gaya hidup terhadap pencegahan osteoporosis pada wanita menopause

\begin{tabular}{lcccccc}
\hline \multirow{2}{*}{$\begin{array}{l}\text { Gaya } \\
\text { Hidup }\end{array}$} & \multicolumn{3}{c}{ Pencegahan } & \multicolumn{2}{c}{$\begin{array}{c}\text { Tidak } \\
\text { Melaku } \\
\text { kan }\end{array}$} & \multicolumn{2}{c}{$\begin{array}{c}\text { Melaku } \\
\text { Kan }\end{array}$} & & & Total \\
& $\mathrm{n}$ & $(\%)$ & $\mathrm{n}$ & $(\%)$ & $\mathrm{n}$ & $(\%)$ \\
\hline Negatif & 58 & 66,7 & 29 & 33,3 & 87 & 100 \\
Positif & 19 & 20 & 76 & 80 & 95 & 100 \\
\hline Total & 77 & 42,3 & 105 & 57,7 & 182 & 100
\end{tabular}

Berdasarkan tabel 7, dari 87 responden dengan gaya hidup negatif, 58 responden $(66,7 \%)$ diantaranya tidak melakukan pencegahan osteoporosis dan dari 95 responden dengan gaya hidup positif, 19 responden (20\%) diantaranya tidak melakukan pencegahan osteoporosis. Hasil uji Chi Square diperoleh $p$ value $=0,000$ ( $p$ value $<\alpha$ ), maka secara statistik terdapat hubungan yang signifikan antara gaya hidup terhadap 
pencegahan osteoporosis pada wanita menopause.

\section{PEMBAHASAN}

\section{Hubungan pengetahuan terhadap pencegahan osteoporosis pada wanita menopause}

Hasil penelitian ini sesuai dengan Notoatmodjo (2012) bahwa pengetahuan merupakan hasil dari indra yang dimiliki oleh manusia atau suatu hasil dari tahu seseorang terhadap objek melewati indra yang dimiliki seperti mata, hidung, telinga dan sebagainya. Jadi seseorang akan menjadi tahu jika ia melihat, mendengar apa yang ada disekitarnya dan mencari tahu apa yang ada disekitar dan disekeliling didekatnya terutama untuk kesehatan dirinya sendiri khususnya dalam melakukan pencegahan osteoporosis.

Penelitian ini juga didukung oleh Keramat et al (2008) bahwa pendidikan dapat mempengaruhi bagaimana gaya hidup seseorang, status gizi maupun status ekonomi seseorang, Maka dari itu pendidikan merupakan bagian dari faktor demografi yang memiliki hubungan dengan osteoporosis. Pengetahuan yang tinggi jika tidak diiringi dengan pendidikan yang tinggi maka pengetahuan tersebut akan sulit dipertahankan, karena pembaharuan dalam dunia kesehatan sangat pesat dan itu bisa didapatkan dengan latar belakang pendidikan yang tinggi dan dukungan keluarga serta bagaimana seseorang tersebut menyikapi pengetahuan yang dapat. Hal ini disampaikan oleh Misnadiarly (2013), terdapat beberapa faktor risiko seseorang dapat terkena osteoporosis yang disebabkan oleh sikap yang buruk terhadap pengetahuan yang ia dapat seperti, gaya hidup yang buruk, kurang melakukan latihan fisik yaitu olahraga, pencandu minuman beralkohol, pecandu kopi, kekurangan asupan kalsium, kekurangan paparan sinar matahari pagi yang mengandung vitamin D.

Hasil penelitian ini sejalan dengan penelitian Setyawati, Fuada dan Salimar (2014) yaitu tidak terdapat hubungan yang signifikan secara statistik pada tingkat pengetahuan tentang osteoporosis. Dalam penelitian ini terdapat beberapa responden yang memiliki pengetahuan yang baik tetapi masih terdapat reponden yang tidak melakukan pencegahan osteoporosis. Hal tersebut disampaikan oleh responden dengan alasan tidak bisa mengkonsumsi susu, tidak memiliki waktu yang luang untuk melakukan olahraga dan melakukan aktivitas dibawah sinar matahari untuk mendapatkan vitamin D. Pada penelitian ini tidak ditemukan adanya hubungan antara pengetahuan terhadap pencegahan osteoporosis ini didasari atas responden yang memiliki pengetahuan yang tinggi tidak menjamin seseorang wanita menopause untuk melakukan, mengaplikasikan ilmu dan pengetahuan yang didapat khususnya dalam pencegahan osteoporosis. Wanita dengan pengetahuan 
Rizka Wildawati ${ }^{1}$, Yecy Anggreny ${ }^{2}$, Dewi Kurnia Putri ${ }^{3}$, Determinan Pencegahan Osteoprosis pada Wanita Menopause

yang tinggi bisa saja tahu dengan pencegahan osteoporosis tetapi belum tentu melakukan pencegahan dengan baik, karena masih banyak faktor yang mempengaruhi mereka tidak melakukan pencegahan salah satunya kesadaran diri untuk menjaga kesehatan, usia yang telah menua sehingga mereka hanya pasrah dengan keadaan, dan pendidikan serta lingkungan yang tidak mendukung.

\section{Hubungan sikap terhadap pencegahan osteoporosis pada wanita menopause}

Hasil penelitian ini sejalan dengan Notoatmodjo (2012) bahwa sikap adalah suatu konsep yang sangat penting dalam sosiopsikologis, karena merupakan suatu kecenderungan terhadap suatu tindakan, berpikir dan berpersepsi. Sikap juga mempunyai suatu daya pendorong atau disebut dengan motivasi. Maka dari itu sikap sangat memberikan pengaruh kepada seorang wanita menopause untuk melakukan pencegahan osteoporosis.

Penelitian ini sejalan dengan yang disampaikan oleh Helmi (2012) kunci dari penanganan osteoporosis adalah mencegah hilangnya sel tulang dengan memakan makanan yang cukup, kebiasaan yang sehat dan melakukan olahraga yang benar dan tepat. Semakin cepat untuk melakukan pencegahan, maka hasil yang akan diterima semakin baik. Maka dari itu pencegahan yang dilakukan dengan baik harus dilakukan sejalan bersama sikap yang positif, karena sikap yang positif dapat mempengaruhi seseorang untuk melakukan tindakan yang baik terutama untuk pencegahan osteoporosis.

Penelitian ini sejalan dengan penelitian Dimyati (2017) dimana pada hasil penelitian ini terdapat hubungan yang signifikan antara sikap terhadap pencegahan osteoporosis. Penelitian ini sejalan dikarenakan sikap positif yang ditunjukkan oleh responden dalam melakukan pencegahan osteoporosis dapat meminimalkan seseorang terhindar dari risiko terjadinya osteoporosis. Sesuai dengan penjelasan tersebut maka dapat disimpulkan bahwa wanita menopause yang memiliki sikap positif terhadap pencegahan osteoporosis memiliki peluang besar untuk tidak terkena osteoporosis, hal ini dikarenakan wanita menopause telah memiliki pengetahuan yang baik tentang pencegahan osteoporosis dan mereka menerapkan perilaku hidup sehat dengan pengetahuan yang baik kemungkinan besar seseorang memiliki sikap positif pula.

\section{Hubungan dukungan keluarga terhadap pencegahan osteoporosis pada wanita menopause}

Penelitian ini didukung oleh Muhith dan Siyoto (2016), dimana dukungan keluarga merupakan suatu dukungan yang sangat dibutuhkan dalam keluarga apabila ada salah satu diantara anggota keluarganya menderita suatu masalah kesehatan atau penyakit. Penerimaan dan pengakuan dari keluarga lainnya sangat dibutuhkan, dengan 
menunjukkan sikap dan tindakan yang terbuka serta membantu penderita dalam mengambil keputusan untuk tindakan selanjutnya seperti proses penyembuhan.

Hasil penelitian ini sejalan dengan penelitian Aprilia dan Puspitasari (2007), dimana terdapat hubungan antara dukungan keluarga terhadap pencegahan osteoporosis, dalam penelitian ini juga disampaikan semakin positif dukungan keluarga yang diberikan maka tingkat kecemasan seseorang wanita menopause akan semakin rendah terhadap masalah kesehatan yang dialami.

Penelitian ini juga didukung oleh penelitian yang dilakukan Muda, Arneliwati dan Novayelinda (2012) dimana hasil penelitian ini menunjukkan bahwa pengetahuan dan sikap keluarga dapat mempengaruhi dalam pencegahan oteoporosis dikarenakan faktor pendidikan dari keluarga. Semakin tinggi pendidikan anggota keluarga maka akan menimbulkan pengetahuan yang tinggi dan sikap yang positif dapat meningkatkan derajat kepercayaan seseorang dalam memberikan dukungan kepada lanjut usia untuk melakukan pencegahan osteoporosis, dukungan yang diberikan keluarga berupa dukungan emosional seperti menemani dan mengantar lansia ke pelayanan kesehatan.

Berdasarkan uraian diatas, dapat disimpulkan adanya hubungan dukungan keluarga terhadap pencegahan osteoporosis pada wanita menopause hal ini didasari oleh sebagian besar keluarga yang memberikan dukungan secara penuh dapat memberikan pengaruh kepada wanita menopause untuk melakukan pencegahan terhadap risiko osteoporosis dengan baik. Dukungan yang dapat diberikan keluarga diantaranya dukungan instrumental seperti memenuhi kebutuhan lansia untuk memeriksa kesehatan di pelayanan kesehatan dan melakukan aktivitas, kemudian dukungan emosional seperti memberikan rasa kasih sayang dan kepedulian. Sedangkan dukungan informasi dan penilaian yang bisa diberikan keluarga berupa mencari dan memberikan informasi mengenai osteoporosis dan pencegahannya, serta memberikan motivasi kepada anggota keluarga untuk melakukan pencegahan osteoporosis.

\section{Hubungan gaya hidup terhadap pencegahan osteoporosis pada wanita \\ menopause}

Hasil penelitian ini sejalan dengan yang dikemukakan oleh Kotler (2002) bahwa gaya hidup merupakan pola hidup yang diekspresikan oleh seseorang dalam bentuk aktivitas, minat, dan opininya. Gaya hidup itu sendiri merupakan gambaran dari keseluruhan diri seseorang dalam berinteraksi dengan lingkungan sekitarnya. Hasil penelitian ini sejalan dengan penelitian Prihartini, Mahirawati, Jahari dan Sudiman (2010) dimana pada penelitian ini terdapat hubungan yang signifikan anatara gaya hidup terhadap pencegahan osteoporosis. Dari penelitian ini 
Rizka Wildawati ${ }^{1}$, Yecy Anggreny ${ }^{2}$, Dewi Kurnia Putri ${ }^{3}$, Determinan Pencegahan Osteoprosis pada Wanita Menopause

juga didapatkan bahwa faktor gaya hidup seperti kebiasaan merokok, mengkonsumsi minuman beralkohol, tidak melakukan olahraga, dan tidak meminum susu tinggi kalsium akan mudah meningkatkan risiko osteoporosis. Jadi gaya hidup sangat memberikan pengaruh besar agar terhindar dari osteoporosis.

Dalam penelitian ini dan dari penjelasan diatas dapat disimpulkan bahwa gaya hidup dapat menjadi salah satu faktor yang dapat mempengaruhi seseorang agar terhindar dari penyakit osteoporosis. Gaya hidup yang ditunjukkan bersifat positif seperti melakukan olahraga, menghindari minuman beralkohol dan bersoda, minum kopi, tidak merokok, meminum susu tinggi kalsium, membatasi garam pada masakan, memakan sayursayuran dan buah-buahan secara rutin dan melakukan aktivitas dibawah sinar matahari untuk mendapatkan vitamin D, jika seseorang dapat melakukan hal tersebut dengan benar maka dapat terhindar dari berbagai masalah kesehatan terutama dari osteoporosis.

\section{SIMPULAN}

Hasil penelitian ini menyimpulkan bahwa sikap, dukungan keluarga dan gaya hidup mempengaruhi wanita menopause dalam melakukan penceghan osteoporosis.

\section{SARAN}

$\begin{array}{ccc}\text { Wanita } & \text { menopause agar dapat } \\ \text { menerapkan } & \text { pencegahan } & \text { osteoporosis }\end{array}$

terutama dalam menyikapi pengetahuan yang didapatkan tentang osteoporosis, merubah gaya hidup lebih sehat dan pihak keluarga dapat membantu pemenuhan kebutuhan kalsium pada wanita menopause.

\section{DAFTAR PUSTAKA}

Aprilia, N. I., \& Puspitasari, N. (2007). Faktor yang mempengaruhi kecemasan pada wanita premenopause. Jurnal Psikologi. Journal Of Public Health, 4(1). Diperoleh dari http://journal.unair.ac.id/filerP DF/makalah\%206_Juli\%202007.pdf. Diakses Pada 15-02-2018 Pukul 15.00.

Dimyati, K. F. (2017). Correlations Between Physical Activity, Smoking Habit And Attitude In Elderly With Incidence Of Osteoporosis. Jurnal Berkala Epidemiologi, 5(1), 107-117. Diperoleh Dari Http://Dx.Doi.Org/10.20473/Jbe.V5i1.2 017.107-117. Diakses Pada 23-02-2018 Pukul 19.37.

Helmi, Z. N. (2012). Gangguan muskuloskletal. Jakarta: Salemba Medika.

Keramat, A., Patwardhan, B., Larijani, B., Chopra, A., Mithal, A., Chakravarty, D., ... \& Khosravi, A. (2008). The assessment of osteoporosis risk factors in Iranian women compared with Indian women. BMC musculoskeletal disorders, 9(1), 28. https://bmcmusculoskeletdisord.biomed central.com/articles/10.1186/14712474-9-28. Diakses Pada 22-022018pukul 20.13.

Kotler, Philip. (2002). Manajemen pemasaran: Edisi Milenium, Jilid 1. Jakarta: Prenhallindo. 
Misnadiarly. (2013). Osteoporosis. Jakarta:

Akademia Permata.

Muda, I., Arneliwati,. \& Novayelinda, R. (2012). Gambaran perilaku keluarga tentang pencegahan osteoporosis pada lansia di Puskesmas Payung Sekaki. Diperoleh Dari Https://Ejurnal.Unri.Ac.Id/Xmlui/Handl e/123456789/1848. Diakses pada 2502-2018 pukul 14.24.

Muhith, A. \& Siyoto, S. (2016). Pendidikan keperawatan gerontik. Yogyakarta: CV Andi Offset.

Mulyani, N. S. (2013). Menopause. Yogyakarta: Nuha Medika

Notoatmodjo, S. (2012). Ilmu Perilaku Kesehatan. Jakarta : PT Rineka Cipta.

Prihatini, S., Mahirawati, V. K., Jahari, A. B., \& Sudirman, H. (2010). Faktor determinan risiko osteoporosis di tiga provinsi di Indonesia. Media Penelitian dan Pengembangan Kesehatan, 20 (2 Jun). Diperoleh Dari Http://Ejournal.Litbang.

Depkes.Go.Id/Index.Php/MPK/Article/ View/787. Diakses Pada 25-02-2018 Pukul 14.50.
Setyawati, B., Fuada, N., \& Salimar, S. (2014). Pengetahuan tentang osteoporosis dan kepadatan tulang hubungannya dengan konsumsi kalsium pada wanita dewasa muda. Jurnal Kesehatan Reproduksi, 5(2), 102-112. Diperoleh dari http://ejournal. litbang.kemkes.go.id/index.php/kespro/ article/view/3887.Diakses pada 03-032018 Pukul 20:28.

Tjahjadi, V. (2009). Mengenal, mencegah, mengatasi sillent killer osteoporosis. Semarang: Pustaka Widyamara. 